\title{
Does Mobile Technology Matter? A Student-Centric Perspective
}

\author{
Wenshin Chen ${ }^{1}$, Venugopal Balijepally ${ }^{2}$ and Peter Sutanto ${ }^{2}$ \\ ${ }^{1}$ Abu Dhabi University, Abu Dhabi, UAE \\ ${ }^{2}$ Prairie View A\&M University, Prairie View, TX, USA
}

\begin{abstract}
Based on a student-centric perspective, this study seeks to understand how mobile technology influences students' learning experiences. Our research motivation is driven by the increasing attention paid to mobile technology in the research and business community. Set in a public university setting, our investigation seeks to shed light on how teaching and learning could be reshaped by mobile technology, most specifically, emerging tablet PCs. The findings, based on two MIS (Management Information Systems) courses, one graduate and the other undergraduate, suggest that overall students perceived the mobility of tablet PC positively. In addition, graduate students expressed a higher degree of learning satisfaction and greater expectation of future technology usage than undergraduate students. Indeed, mobile technology seems to matter to students' learning in general. The finding is particularly relevant when considering how to incorporate mobile technology into teaching practice as such technology-driven teaching practice is increasingly being expected in the contemporary networked society. Additional insights for managers, technology vendors, and college instructors are also discussed.
\end{abstract}

Keywords: mobile technology, student satisfaction, learning experiences, tablet PC, case study

\section{Introduction}

It is widely recognized that mobile technology has become increasingly influential in the business world. Business managers and technology practitioners have long predicted that mobile technologies would lead to significant changes in the business processes. Some popular examples include smart devices and sensor networks enabling a remotely controlled wireless environment for home appliance and emerging RFID (Radio Frequency Identification) tags implanted into customers' arms helping clubs to track purchasing records (Anonymous, 2007). Consequently, the applications of mobile technologies are increasingly incorporated into many sectors. In the health care industry, for instance, physicians were being provided with wireless devices to enhance their productivity and improve medical services (Fiser, 2004); medical students were increasingly being expected to get equipped with smart mobile devices prior to their entry to the programs (Rege and Kean, 2003).

In the agriculture sector, the implementation of wireless local area networks (WLANs) has substantially improved data communications among farming equipments and relevant activities that are traditionally considered as lowtech businesses (McKinion, Turner, Willers, Read, Jenkins and McDade, 2004). In the oil and energy industry, emerging WiMAX (Worldwide Interoperability for

Copyright (c) 2012 Wenshin Chen, Venugopal Balijepally and Peter Sutanto. This is an open access article distributed under the Creative Commons Attribution License unported 3.0, which permits unrestricted use, distribution, and reproduction in any medium, provided that original work is properly cited. Contact author: Wenshin Chen E-mail: wenshinchen@hotmail.com 
Microwave Access) networks have increasingly enabled continuous data transfer in remote oil fields where traditional network infrastructure is practically non-existent (Hoskins, 2007). In the public sector, a growing number of cities in the U.S. have launched regional wireless networks. In the U.K., the River Thames in London has been transformed into a popular hotspot with wireless access being provided along its river bank and subsequently helps reshape local residents' life style (McCue, 2007).

In the education systems, school teachers have sought ways to incorporate mobile technology into the teaching pedagogy to better increase students' learning interests (Patterson, 2001); many private schools have even adopted laptop programs for students so that their learning can go beyond the traditional physical and temporal boundaries (Rajala, 2003). Among college campuses, wireless networks and mobile technology have increasingly become omnipresent. The new generations of students will consider wireless networks and mobile technology as a part of normal college learning and campus life. Incorporating wireless networks and mobile technology is increasingly expected for college campuses to legitimize their higher education status (Chen and Bennett, 2006). It, however, remains to be seen how the use of wireless networks and mobile technology changes teaching and learning processes.

This research, thus, seeks to investigate how mobile technology affects learning experiences in a college setting. More specifically, we inquire how college students perceive mobile technology to be enhancing their learning experiences, and to what extent do the perceptions differ among various student groups. Given the fact that the mainstream IS education journals have tended to focus on other emerging topics such as virtualization (Lunsford, 2009), Web 2.0 (Harris and Rea, 2009), Second Life (Schiller, 2009) and/ or traditional teaching and learning practice such as IS developers' communication skills (Qurban and Austria, 2009), design principles for learning environment
(Rondeau and Li, 2009), and project management skills (Smith, Smarkusky and Corrigall, 2008), our research investigation could make empirical contribution to the existing IT education field by helping understand how IT teaching and learning experiences are transformed with mobile technologies. This is particularly significant in today's higher education not just from the teaching practice's perspective but also from the viewpoint of globalized education system and networked economy where network infrastructure and mobile technologies in particular are increasingly integrated into classroom teaching and student learning (Chen and Bennett, 2010).

The remaining paper is organized as follows. First, the research method is discussed including the organization site in which the research investigation took place and the process through which data was collected. Next, current findings are presented, followed by the discussion of the significance of the results. In the Implications section, insights and practical lessons are drawn for IT instructions in today's networked learning environments. Finally, research limitations and reflection on future research directions are discussed.

\section{Research Method}

Due to the relatively emerging nature of mobile technology in higher education and lack of sufficient empirical literature to guide our research investigation, we embarked on a case study research methodology to gain an in-depth understanding of students' learning experiences over time. Case study research methodology is appropriate for our research as it facilitates in-depth analysis of situations within specific settings (Eisenhardt, 1989), particularly for exploratory investigation (Yin, 1994). While case study could involve many data collection techniques, our investigation largely relies on participant observations and a short user survey that summarizes the students' experiences of mobile technology. The specific mobile technology chosen was tablet PCs that incorporated many emerging functionalities for teaching and learning. In addition, wireless access 
points installed in classrooms provided connection to the network infrastructure that supported mobility. The organizational setting and the data collection process are further elaborated in the sections that follow. A copy of survey questionnaire is listed in the Appendix.

\section{Organizational Site}

The organization for the case study is a relatively small public university located in southwest U.S.A. It was chosen largely due to a research grant received from an external grant agency. The purpose of the research grant is to incorporate mobile technology into teaching and learning process in the IT (information technology) courses and seek in turn to enhance students' learning experiences. The tools and equipment received through the research grant were used to provide students immediate hands on experiences of mobile technology in a classroom setting so as to free them from the limitations of physical space or computing resources. The classroom setting utilized tablet PCs and the existing campus wide wireless LAN (Local Area Network) to provide a more interactive, resourceful classroom atmosphere that centered on students' learning experiences and satisfaction.

The investigation took place in the college of business which is an AACSB (Association to Advance Collegiate Schools of Business) accredited institution. The case study was conducted in the MIS (management information systems) program. A majority of the students who enroll in the college and the university come from social and/ or economic disadvantageous backgrounds. Hence, many students in the college did not have access to adequate computing resources at home.

\section{Data Collection Process}

The data collection began in Fall 2008 in two MIS courses taught by one of the coauthors: Java Applications in Business, a technical course where students learned Java programming and engaged in hands on development of Java code, and Applied Database Management, another technical course where students learned to design and implement database applications. The former was an undergraduate while the latter was a graduate course. Students were provided with tablet PCs during class time and encouraged to use them for note taking and class related work. Student perceptions of the usefulness of the tablet PCs and their learning satisfaction with the use of tablet PCs were collected and analyzed at the end of the semester. The study was again repeated in the Spring 2009 semester in two MIS courses: Java Applications in Business and Business Database Applications; both of which were undergraduate courses.

Specific features of tablet PCs relevant to the case study included their wireless connectivity, swivel neck, handwriting recognition, and writing enabled screen with stylus pen for annotating notes and slides.

In all, thirty two students were involved in the study across three courses: ten in graduate database course (Fall 2008), fifteen in undergraduate Java course (nine in Fall 2008 and six in Spring 2009), seven in undergraduate database course (Spring 2009). In terms of gender composition, there were fifteen male and sixteen female students with one student leaving the gender field blank. All the students involved provided the survey responses.

\section{Analysis and Findings}

The findings reported in this paper are based on data collected from Fall 2008 to Spring 2009. The results were analyzed by student perceptions of their learning experiences and by their perceived usefulness of mobile technology. The former included student perceptions of learning satisfaction, expectation of future use, expectation of better learning, prior awareness of tablet $\mathrm{PC}$, and prior experience of tablet $\mathrm{PC}$; the latter comprised students' perceived usefulness of nine different features of tablet PC and its mobility. The results were analyzed by gender, course, and student type as presented in the following sections. 


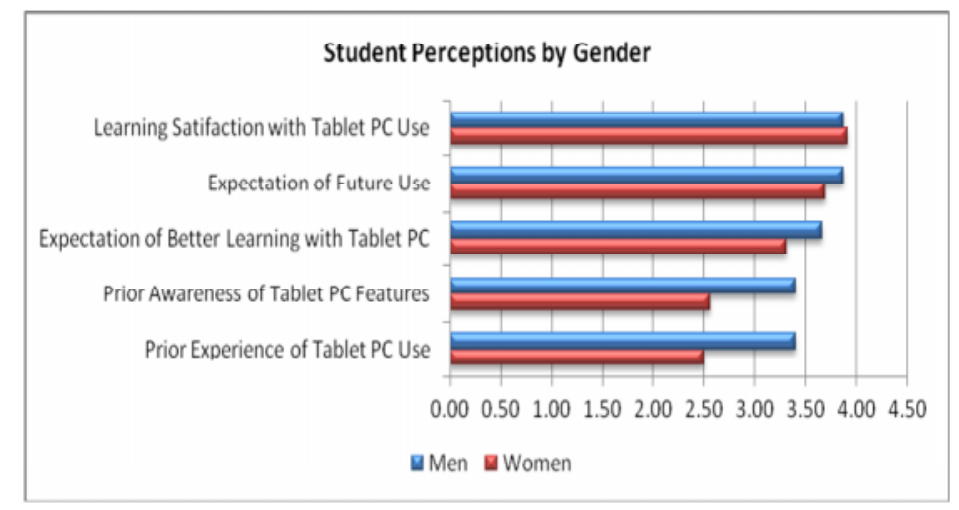

Fig.1 Student Perceptions by Gender

\section{Student Perceptions by Gender}

Three major findings are drawn concerning the gender difference in student perceptions. First, while the prior awareness and experience of tablet PC use was low, irrespective of gender, male students indicated marginally higher prior awareness of tablet PC features and prior experience of using tablet PC. Second, the learning satisfaction with tablet PC was uniformly high, irrespective of the gender. Third, male students indicated marginally higher expectation of better learning and future use of tablet PC than female students.

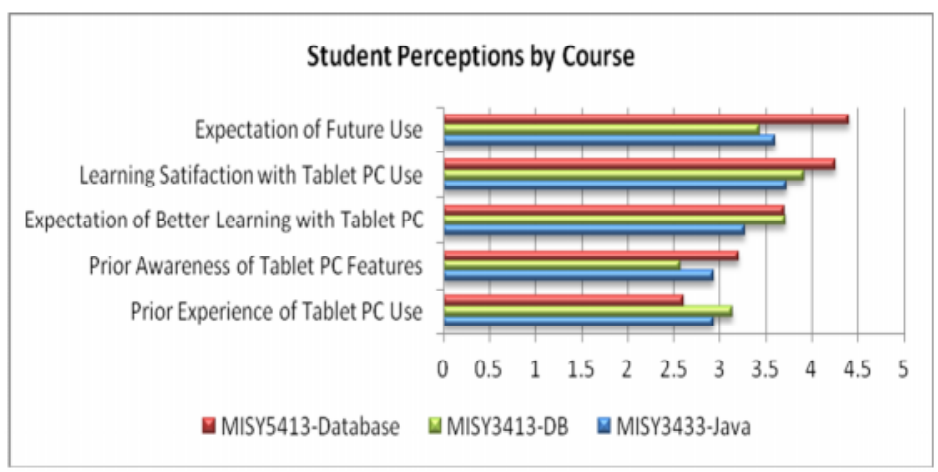

Fig.2 Student Perceptions by Course

\section{Student Perceptions by Course}

Another three inferences are apparent in the differences of students' perceptions concerning mobile technology across different courses (where MISY 5413 was a graduate course of database management, MISY 3412 was an undergraduate database management course, and MISY 3433 was Java programming course at the undergraduate level). First, while many students had prior awareness of tablet PC features, the prior experience of tablet PC use was low. Second, irrespective of the course, students indicated high satisfaction with tablet PC use in the course. Also, students had positive expectation of using the tablet PC in the near future. Third, students in the graduate database course however indicated marginally higher learning satisfaction and higher expectation of future use than students in the other two courses.

\section{Student Perceptions by Student Type}

Similarly, Different Students (I.E. Graduate Vs. Undergraduate) Appeared To Have Slightly Different Perceptions. As Demonstrated In The Figure Below, While 
Many Students Had Prior Awareness Of Tablet PC Features, Their Prior Experience Of Tablet PC Use Was Low. In Addition, Both Graduate And Undergraduate Students Indicated High Satisfaction With Tablet PC Use In The Course And Had High Positive Expectation Of Using The Tablet
PC In The near future. Most importantly, graduate students reported lower prior experience with tablet PC than undergraduate students, but have reported higher prior awareness of tablet PC features, higher learning satisfaction and have higher expectation of future use.

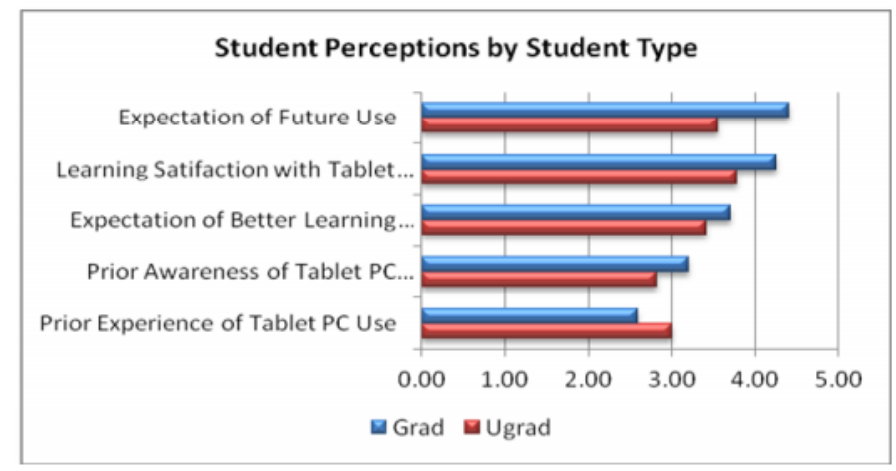

Fig.3 Student Perceptions by Student Type

\section{Perceived Usefulness of Tablet PC Features by Gender}

As for gender differences in perceiving usefulness of tablet PC, both male and female students valued the lightweight and resultant portability of the tablet PC highly, while button mouse feature was ranked lowest in terms of usefulness. Also, female students in general rated the usefulness of tablet PC features marginally higher than did male students.

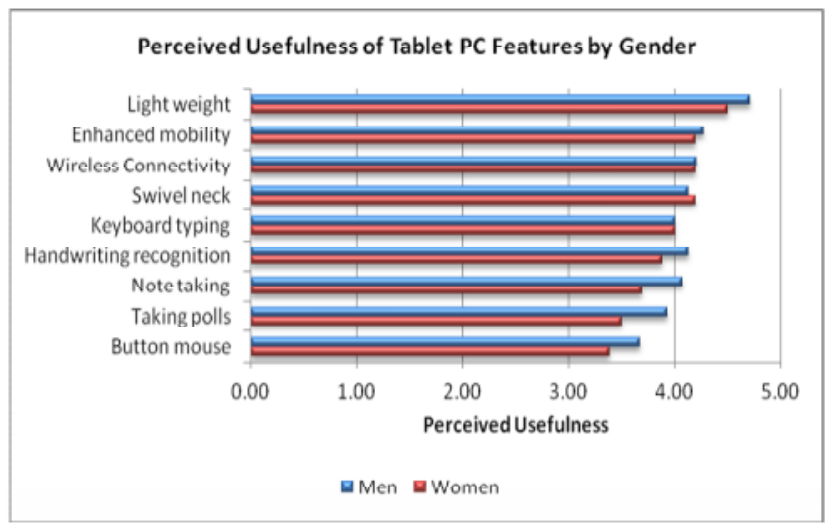

Fig.4 Perceived Usefulness of Tablet PC Features by Gender

\section{Perceived Usefulness of Tablet PC Features by Course}

Students in different courses did not demonstrate much variation in perceived usefulness of tablet PC. As shown below, irrespective of the course, students valued the lightweight and resultant portability of the tablet PC highly and ranked the usefulness of button mouse feature relatively low. Moreover, students in graduate database course rated the usefulness of various tablet PC features more highly than did students in other courses. 


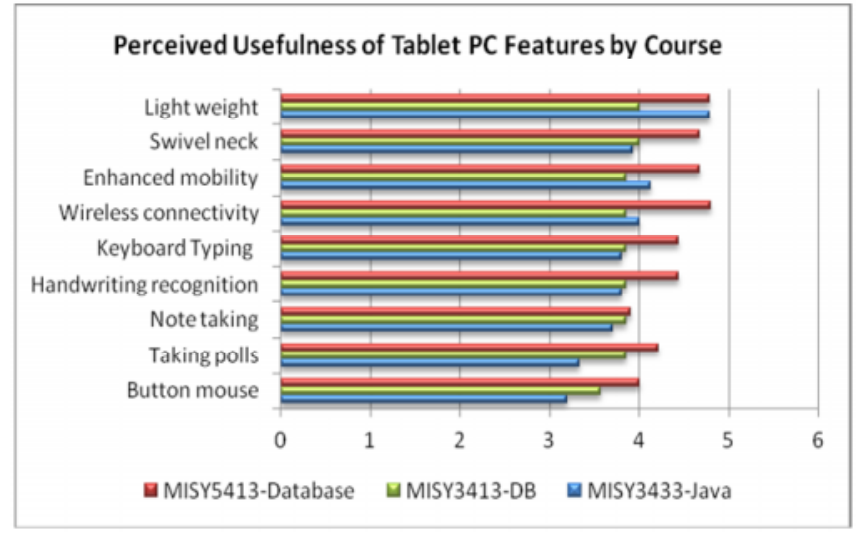

Fig.5 Perceived Usefulness of Tablet PC Features by Course

\section{Perceived Usefulness of Tablet PC Features by Student Type}

Finally, student type seemed to play a significant role in their perception of usefulness of tablet PC. More specifically, graduate students generally rated the usefulness of various tablet PC features more highly than undergraduate students did.

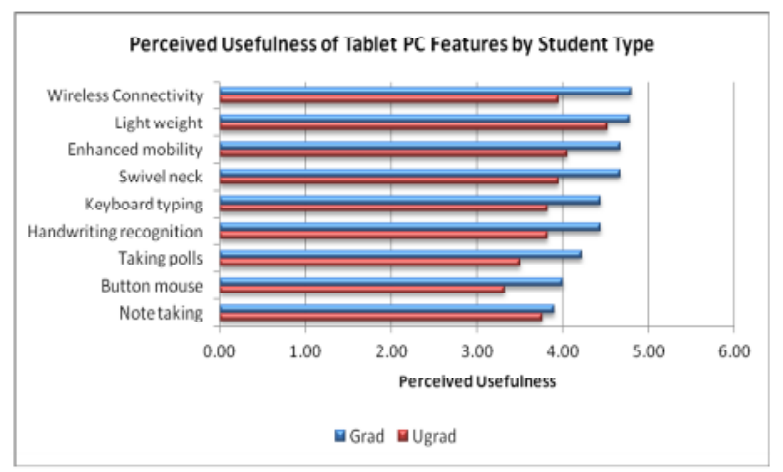

Fig.6 Perceived Usefulness of Tablet PC Features by Student Type

\section{Discussion}

This research inquired how college students perceive mobile technology in enhancing their learning experiences, and to what extent do the perceptions differ among various student groups. Regarding the first research question, the current findings suggest that irrespective of gender, course, or student type, students reported relatively high satisfaction about tablet PC in classroom settings. Perhaps on this account, they also reported high expectation of better learning and future use of tablet PC. At the same time, their prior awareness and experience of tablet
PC were commonly low across different student groups. These results could be expected since most undergraduate students came from socially and economically disadvantaged backgrounds. When prior experience and awareness are low, the technology would naturally be more appealing and perhaps fascinating. The general high expectation and satisfaction of learning experiences and high expectation of future use among students is therefore quite plausible.

With respect to specific features of tablet PC, students seem to consider wireless connectivity, light weight, enhanced mobility, and swivel neck among the most 
useful functions of tablet PC that would help them to enhance their classroom learning experiences. Interestingly, these features are all related to the notion of 'mobile' technology because they all help enable the user's mobility and in turn create a more convenient and efficient learning environment. It is thus reasonable to state that the students in general highly regard mobile technology in enhancing their learning experiences.

As for the second research question, three noticeable differences could be observed in students' perceptions across different groups. First, male students in general reported having higher prior awareness and experience, which might in turn correlate to their higher expectation of learning outcomes. These differences fit with the traditional perceptions on gender differences in information technology. The second noticeable difference was observed between students in database and in Java courses. Students in database courses tended to have both higher expectation of better learning and higher learning satisfaction at the same time. This seems to indicate that the students' expectation of better learning was met and their learning satisfaction was thus reported high. A possible explanation of this difference might be attributed to the nature of courses. Since Java programming was a much more technically complex course than database management, the utilization of tablet PC for the course would not be as easy or as engaging as in database courses. The difficulty to incorporate the features of Java teaching and learning would thus lead to lower expectation and satisfaction of the technology.

The third difference was rather noticeable between graduates' and undergraduates' perceptions of expectation of better learning, learning satisfaction, and expectation of future use. Since the demographics between undergraduate and graduate students at this university did not appear to be remarkably different, a possible explanation for this finding is that graduate students tended to be more motivated than undergraduate students, and hence more focused on learning outcomes and in turn reported higher expectation of better learning. At the same time, this group of graduate students reported relatively lower prior experience but higher awareness of tablet PC. This suggests that while they were aware of the technology, they lacked opportunities to actually experience it. This case study setting provided them a chance to experience the technology practically. Their learning satisfaction was thus greatly enhanced.

With respect to specific features of tablet $\mathrm{PC}$, the difference in perceptions is most evident between graduate and undergraduate groups. Graduate students reported higher perceived usefulness than did undergraduate students concerning almost all features of tablet PC while differences in gender or courses did not appear noteworthy. Again, this finding might be better attributed to different motivation levels of graduate and undergraduate students than due to any demographic factor.

\section{Implications}

From the analysis and findings, two primary implications are drawn for practitioners: (1) the mobility of technology possesses potential to enhance learning experiences, and (2) teaching practice needs to be reshaped to incorporate emerging mobile technology for better learning experiences.

As discussed previously, specific features of tablet PC valued most highly by students were more related to its mobility (i.e. wireless connectivity, light weight, enhanced mobility, and swivel neck) than to other functionalities. Those who valued the mobility of tablet PC, most notably graduate students, also reported higher learning satisfaction, expectation of better learning and future use of tablet PC. It is thus reasonable to state that mobility is a stronger influential factor than other technological features in enhancing learning experiences. For business vendors, this suggests that future design of technology can be more innovative, particularly with regards to its mobility. Users appreciate the opportunity to work without the constraint of physical boundary. While other functions are important such as note-taking and handwriting recognition, they might be taken for granted in classroom settings and 
thus will not provide distinctive impression of innovation.

For teaching practice, this implication suggests that instructors could better utilize the mobility of emerging technology to enhance the students' learning experiences. A possible scenario would be to enable group discussions or case studies that utilize the mobility of tablet PC. Students could be provided with mobile accessibility anywhere on campus to their tablet PC or other technologies and are supposed to report the results of their case discussion at the end of the class session. In doing so, the students will be situated in a more relaxing and improvised atmosphere that breaches the traditional boundary of learning environment (i.e. classroom settings). The disappearance of traditional learning boundary symbolizes a different learning mode and may in turn allow students to be more creative and freethinking in analyzing case studies.

A second implication is that traditional teaching practice could better incorporate emerging mobile technology. As our findings demonstrate, technical courses such as Java programming seem to have lower student appreciation of mobile technology and it might be mostly due to the nature of course where technical teaching could not be easily transformed with emerging technology. In such programming courses, note taking and other features of tablet PCs appear less valuable than in other courses such as database courses. Vendors involved with the design of mobile technology could thus further consider incorporating technical features so that programming syntax and code can be better demonstrated through mobile technology in classroom settings. For teaching practice, given the current technical features, instructors could consider changing traditional programming exercises in classrooms. One possible solution is to present each programming exercise as a case study and equip the students with mobile technology so that they could discuss and analyze syntax and code in groups, anywhere on campus. While this practice is expected to enhance the students' learning experience, it requires substantial effort from the instructors and certain level of academic preparation from the students. As for nontechnical courses, with greater incorporation of emerging mobile technology, higher learning satisfaction and positive experience could likely result.

\section{Conclusion}

This teaching study has investigated how mobile technology enhances student learning experiences and found that the mobility features of technology appear to reshape the students' learning satisfaction and future expectation of technology. Also, different student groups, particularly graduate vs. undergraduate students, demonstrated different levels of learning satisfaction and expectation with the same technology. Most importantly, the implications drawn from the study suggest that changing traditional practice and better incorporating technology into teaching practice might be as significant as technical features and functionalities. These findings and suggestions provide technology vendors and instructors with insights to reshape the technology and the instruction, respectively.

However, the study has several inevitable limitations. First, it is from one single case study, which is situated in a unique social and economic background. The findings and suggestions made can only serve as practical lessons instead of generalizable outcomes. As is apparent, the size of student groups is not equal across different units. The comparisons made are therefore merely intended to provide a broad understanding of students' perceptions. Future studies could thus deepen the current insights by extending case studies or soliciting larger samples for achieving more generalizable findings.

\section{Acknowledgement}

The authors thank HP Technology for Teaching Higher Education Grant for its financial and technological support that made this research project possible. An earlier version of this paper appears in the proceedings of the 15th IBIMA conference held in Cairo, Egypt, 2010.

\section{References}

Anonymous (2007). 'A World of Connections (Cover Story),' Economist 383 (8526), 3-4. 
Anonymous (2007). 'The Hidden Revolution (Cover Story),' Economist 383 (8526), 17-18.

Chen, W. \& Bennett, D. (2010). “When CostEfficient Technologies Meet Politics: a Case Study of Radical Wireless Network Implementation," Communications of IBIMA, 2010 (2010), 12 Pages.

Eisenhardt, K. M. (1989). "Building Theories from Case Study Research," Academy of Management Review, 14 (4), 532-550.

Fiser, D. (2004). "Wireless Technology Empowers Physicians," Health Management Technology 42.

Harris, A. L. \& Rea, A. (2009). "Web 2.0 and Virtual World Technologies: a Growing Impact on Is Education," Journal of Information Systems Education, 20 (2), 137144.

Hoskins, R. "Yemen Oilfields Build Wimax Network," [Online], [Retrieved April 22 2007]. Www.Bbwexchange.Com.

Lunsford, D. L. (2009). "Virtualization Technologies in Information Systems Education," Journal of Information Systems Education, 20 (3), 339-348.

Mccue, A. "Thames Becomes Giant Wi-Fi Hotspot," [Online], [Retrieved April 22]. Http:/ / Networks.Silicon.Com/ Mobile/ 0,39 024665,39166596,00.Htm.

Mckinion, J. M., Turnera, S. B. , Willersa, J. L. , Reada, J. J. , Jenkinsa, J. N. \& John McDade (2004). "Wireless Technology and Satellite Internet Access for High-Speed Whole farm Connectivity in Precision Agriculture," Agricultural Systems, 81 (3), 201-212.
Patterson, J. C. (2001). "Kids on the Run: Mobile Technology," Technology \& Learning 44-47.

Qurban, M. H. \& Austria, R. D. (2009). "Improving the Communication Skills of is Developers during Requirements Elicitation Using Experiential Learning," Journal of Information Systems Education 20 (3), 301-311.

Rajala, J. B. (2003). “Wireless Technology in Education,” T.H.E Journal, 31 (3), 28.

Rege, O. \& Kean, J. (2003). "Mobile Technology Goes to Medical Schools," Wireless Systems Design 18, 20.

Rondeau, P. J. \& Li, X. (2009). 'An Exploratory Review of Design Principles in Constructivist Gaming Learning Environments,' Journal of Information Systems Education 20 (4), 289-300.

Schiller, S. Z. (2009). "Practicing LearnerCentered Teaching: Pedagogical Design and Assessment of a Second Life Project," Journal of Information Systems Education, 20 (3), 369-381.

Smith, H. III, Smarkusky, D. \& Corrigall, E. (2008). "Defining Projects to Integrate Evolving Team Fundamentals and Project Management Skills," Journal of Information Systems Education 19 (1), 99-110.

Yin, R. K. (1994). Case Study Research: Design and Methods, SAGE Publications Thousand Oaks, CA. 


\section{Appendix}

\section{Survey Questionnaire}

1. Class:

2. Semester:

3. Gender (Please indicate F or $\mathrm{M})$ :

Please Select The Best Option That Describes Your Perception On The Following:

4. I have experience using tablet PC before this class?

- Strongly disagree

2. Disagree

3. Neutral

4. Agree

5. Strongly agree

5. I was aware of the features of tablet PC before this class?

- Strongly disagree
2. Disagree

3. Neutral

4. Agree

5. Strongly agree

6. Using tablet PC would help me to learn the course material better

- Strongly disagree

2. Disagree

3. Neutral

4. Agree

5. Strongly agree

7. Using tablet $\mathrm{PC}$ would me to master the course material better

- Strongly disagree

2. Disagree

3. Neutral

4. Agree

5. Strongly agree

8. The following Tablet PC features were very useful to me in this course?

\begin{tabular}{|l|l|l|l|l|l|}
\hline \multicolumn{1}{|c|}{ Feature } & $\begin{array}{c}\text { Not at } \\
\text { all }\end{array}$ & $\begin{array}{c}\text { Not } \\
\text { much }\end{array}$ & Neutral & Somewhat & $\begin{array}{c}\text { Very } \\
\text { much }\end{array}$ \\
\hline $\begin{array}{l}\text { Wireless } \\
\text { connectivity }\end{array}$ & & & & & \\
\hline $\begin{array}{l}\text { Swivel neck to fold } \\
\text { screen up }\end{array}$ & & & & & \\
\hline $\begin{array}{l}\text { Note taking using } \\
\text { stylus }\end{array}$ & & & & & \\
\hline Typing text & & & & & \\
\hline Increased mobility & & & & & \\
\hline light weight & & & & & \\
\hline button mouse & & & & & \\
\hline $\begin{array}{l}\text { handwriting } \\
\text { recognition }\end{array}$ & & & & & \\
\hline Taking polls & & & & & \\
\hline
\end{tabular}

9. How do you feel about your overall learning experience of using tablet PC in this course?

- Very Dissatisfied $\begin{array}{lll}3 & 4 & 5\end{array}$

- Very Displeased $3 \quad 4 \quad 5$

- Very Frustrated $\begin{array}{lll}3 & 4 & 5\end{array}$

- Absolutely Terrible 34 5
10. I would be using tablet PC for my personal use in the next two years?

- Strongly disagree

2. Disagree

3. Neutral

4. Agree

5. Strongly agree

11. How could tablet PC be used more effectively in the class?

12. What did you like about using tablet PCin the class? 